\title{
CONJUNCTIVAL SWAB CULTURE IN DIABETIC RETINOPATHY PATIENTS
}

\author{
${ }^{1}$ Osama Abdelkader Salem, ${ }^{1}$ Raafat Aly Rehan, ${ }^{1}$ Nesrine Said Madkour, ${ }^{2}$ Noha Alaa \\ EL-Din Fahim, and ${ }^{3}$ Aml Yahia Elmetwally Ahmed
}

\begin{tabular}{l}
\hline \\
${ }^{1}$ Department of Ophthalmology \& \\
${ }^{2}$ Department of Clinical Pathology \\
Faculty of Medicine, Ain Shams \\
University, Cairo, \\
${ }^{3}$ Minyat El Nasr Hospital at \\
ElDakahlia Government \\
Egypt. \\
Corresponding author \\
Aml Yahia Elmetwally Ahmed \\
Mobile: (+2) 01001369058 \\
E.mail: \\
amlyahia1988@ gamil.com \\
Received: 16/6/2021 \\
Accepted: 13/7/2021
\end{tabular}

Online ISSN: 2735-3540

\begin{abstract}
:
Background: The normal flora of the eye plays an important role in maintaining ocular homeostasis by various mechanisms. They comprise mainly bacteria which do not cause infection in normal conditions but can be a main source of infection after ocular surgery, trauma or in immunocompromised patients. Immune function is compromised in diabetes mellitus. Patients with diabetes mellitus (DM) are prone to infection because glucose in the skin, urine, mucous membranes and tears promotes growth of microorganism.
\end{abstract}

Aim of the Work: To detect the presence of pathogenic bacteria other than floral bacteria which are important pathogens of ocular infections in diabetic patients.

Patients and Methods: This cross-sectional descriptive study was carried out on sixty eyes of sixty patients attending ophthalmology outpatients clinic at Ain Shams University Hospitals. The study was conducted in accordance with the ethical standards stated in the Faculty of Medicine with informed consent obtained.

Results: Among 60patients, 26 were males and 34 were females, 35 had NPDR (58\%), 25 had PDR (44\%), 24 on OHG (40\%) ,36 on insulin (60\%). Growth of some bacteria was seen in 29 patients (48.3\%) out of 60 eyes. The commonest flora isolated was staph coagulase negative (Staph CONg) 31.7\%, next was candida 16,7\%. Mixed infections had been found in many patients, $57.77 \%$ of male subjects had sterile conjunctiva compared to $47.1 \%$ in the females. The swab culture of rest of the subjects showed that Staph CONg were the predominant normal flora in both $30.8 \%$ and $32.4 \%$ in males and females respectively. However, Candida species were found significantly higher in females $23.5 \%$. Positive conjunctival culture was found higher in patients on insulin than $O H G$, although staph cong, non-hemolytic streptococcus \&candida were found higher in patients on insulin therapy but there had no statistical significance, candida was found higher in stage of NPDR than PDR and had statistical significance.

Conclusion: Gram-positive bacteria and candida were detected in higher ratios in the conjunctival flora of diabetic patients. Considering that flora elements may be important pathogens in ocular infections, treatment approaches to gram-positive bacterial and fungal infections should not be ignored in cases of ocular infections in diabetics.

Keywords: Diabetes mellitus, conjunctival culture, normal flora, staph coagulase negative, candida. 


\section{INTRODUCTION:}

Eyelids and conjunctiva harbor a significant number of bacteria from the external environment and are called normal flora. They play an important role in normal body functions and health by secreting bacteriocins and chemical mediators to maintain surface homeostasis and immunoregulation. They prevent colonization by pathogenic organisms. ${ }^{(1)}$

Some members of the conjunctival flora play a pathogenic role in diabetes mellitus when immune function is compromised, which may lead to serious infection. ${ }^{(2)}$

Diabetes, a lifelong progressive disease, is the result of body's inability to produce insulin or use insulin to its full potential, and is characterized by high circulating glucose. (3)

Diabetes is a chronic disease and sustained hyperglycemia attacks both microvessels and macrovessels throughout the body. Diabetic retinopathy, a disease of the retina, is the leading cause of acquired blindness in working adults. The microvasculature of the retina is damaged, the blood vessels swell and leak fluid, and if not prevented, new vessels start to grow, and ultimately lead to the detachment of the retina. ${ }^{(3)}$

In the development of diabetic retinopathy, the basement membrane thickens, the blood flow is altered, and pericytes and endothelial cells undergo accelerated apoptosis resulting in pericyte ghosts and acellular capillaries. The leukocytes become less deformable, and retinal leukostasis is increased affecting endothelial function. ${ }^{(4)}$

Diabetic retinopathy can be classified into two stages: nonproliferative and proliferative. The earliest clinical signs of nonproliferative diabetic retinopathy are microaneurysms and retinal hemorrhages. Development of cotton wool spots, venous beading and intraretinal microvascular abnormalities are hallmarks of progressive capillary perfusion. ${ }^{(5)}$

Neovascularization on the surface of the retina and optic disc in conjunction with further retinal ischemia signifies the presence of proliferative diabetic retinopathy. ${ }^{(5)}$

The identification of bacteria in the laboratory is particularly relevant in medicine, where the correct treatment is determined by the bacterial species causing an infection. Consequently, the need to identify human pathogens was a major impetus for the development of techniques to identify bacteria. ${ }^{(6)}$

The Gram stain, developed in 1884 by Hans Christian Gram, characterizes bacteria based on the structural characteristics of their cell walls. ${ }^{(7)}$

The thick layers of peptidoglycan in the "Gram-positive" cell wall stain purple, while the thin "Gram-negative" cell wall appears pink. By combining morphology and Gramstaining, most bacteria can be classified as belonging to one of four groups (Grampositive cocci, Gram-positive bacilli, Gramnegative cocci and Gram-negative bacilli). Some organisms are best identified by stains other than the Gram stain, particularly mycobacteria or Nocardia, which show acidfastness on Ziehl- Neelsen or similar stains. $^{(8)}$ Other organisms may need to be identified by their growth in special media, or by other techniques, such as serology. ${ }^{(9)}$

Culture techniques are designed to promote the growth and identify particular bacteria, while restricting the growth of the other bacteria in the sample. Often these techniques are designed for specific specimens. ${ }^{(9)}$

The choice for the prophylactic topical antibiotic is influenced by factors as spectrum of bacteria covered, the rapidity with which the antibiotic eliminates bacteria from the conjunctival surface, the duration of action, the penetration and toxicity of the 


\section{Conjunctival Swab Culture In Diabetic Retinopathy Patients}

antibiotic, the antibiotic susceptibility pattern and the cost. ${ }^{(10)}$

To reduce the risk for postoperative infectious endophthalmitis, the primary intraoperative objective is to minimize entry of organisms into the anterior chamber. ${ }^{(11)}$

\section{AIM OF THE WORK:}

To detect the presence of pathogenic bacteria other than floral bacteria which are important pathogens of ocular infections in diabetic patients.

\section{PATIENTS AND METHODS:}

Sixty eyes of 60 patients were recruited from Ophthalmology Clinic, Ain Shams University Hospital. They were asked to participate and were enrolled in this study in the period from $1^{\text {st }}$ of November to $15^{\text {th }}$ December 2020. This study was designed as a cross sectional descriptive study. The report is based on bacteriological culture results of healthy conjunctiva of diabetic retinopathy patients visiting the Eye Outpatient Department.

Inclusion criteria: All diabetic retinopathy patients.

Exclusion Criteria: Patients with any active ocular infection and patients using topical antibiotics.

Study design: The study was conducted according to the ethical standards stated by the ethical committee of Ain Shams University Hospitals and all patients were evaluated by: full physical examination with review of medical history, ophthalmic workup, conjunctival swab culture and laboratory identification of microorganisms.

Ophthalmic workup consisted of: Best corrected visual acuity measurement using Snellen's chart with conversion of the values to Logarithm of minimum angle of resolution (Log MAR) for statistical analysis, external examination of the eye lid and conjunctiva, anterior segment examination using slit lamp biomicroscopy, posterior segment examination using indirect ophthalmoscope and slit lamp biomicroscopy with $90 \mathrm{D}$ volk lens for assessment of the macula and optic nerve. Following fundus examination patients were divided into non proliferative diabetic retinopathy (NPDR) and proliferative diabetic retinopathy (PDR) according to signs in fundus.

Study Procedure: Disposable sterile cotton swab with Stuart transport medium tube were used for specimen collection. Each specimen was labeled with participant's name, age, sex, date and time of specimen collection. Patients were asked to look up and gently pull down the lower lid exposing the conjunctiva. The swab stick was gently swept along the lower fornix from inner to outer canthus taking care not to touch the eyelids. The swab was immediately placed into bacterial medium container, then the patient was asked to close the eye for a few seconds.

Conjunctival swab culture: Swabs were directly inoculated using the quadrant technique onto blood agar, chocolate agar, and MacConkey agar. All blood and MacConkey plates were incubated under aerobic conditions at $36 \pm 1{ }^{0} \mathrm{C}$ while the chocolate agar plates were incubated in specific jars with $10 \% \mathrm{CO} 2$ at $36 \pm 1{ }^{\circ} \mathrm{C}$. All agar plates were examined after $48 \mathrm{~h}$. In case of growth of any colonies on the culture plates, they were further identified using the routine microbiological techniques. However, if the culture plates revealed no growth they were reported as no growth after 48 hours incubation.

\section{Statistical analysis and data interpretation:}

Data were fed to the computer and analyzed using IBM SPSS Corp. Released 2013. IBM SPSS Statistics for Windows, 
Version 22.0. Armonk, NY: IBM Corp. Qualitative data were described using number and percent. Quantitative data were described using mean, standard deviation for parametric data after testing normality using Kolmogrov-Smirnov test. Significance of the obtained results was judged at the $(0.05)$ level.

Data analysis Qualitative data: ChiSquare test for comparison of 2 or more groups. Fischer Exact test was used as correction for Chi-Square test when more than $25 \%$ of cells have count less than 5 in 2 by 2 tables.
Quantitative data between groups: Parametric tests: Student t-test was used to compare 2 independent groups \& Non Parametric tests: Mann-Whitney U test was used to compare 2 independent groups. A Pvalue of 0.05 or less was considered statistically significant and that of 0.01 or less was considered highly statistically significant.

\section{RESULTS:}

1- Sex distribution among study groups:

Among 60 patients, 26 were males and 34 were females as in table (1).

Table (1): demographic characteristics of the studied cases.

\begin{tabular}{|c|c|c|}
\hline \multicolumn{3}{|c|}{ Total number $=60$} \\
\hline Age/year & & \\
\hline Mean SD & \multicolumn{2}{|c|}{$56.45 \pm 7.87$} \\
\hline Range & \multicolumn{2}{|c|}{$(33.0-73.0)$} \\
\hline Sex & $\mathrm{N}$ & $\%$ \\
\hline Males & 26 & $43.3 \%$ \\
\hline Females & 34 & $56.7 \%$ \\
\hline
\end{tabular}

2- Stages of retinopathy among studied cases:

Among 60 diabetic retinopathy patients 35 had NPDR (58\%), 25 had PDR (44\%) as in table (2).

Table (2): Stages of retinopathy among studied cases

\begin{tabular}{|l|c|c|}
\hline & $\mathrm{N}=60$ & $\%$ \\
\hline RetinopathyNPDR & 35 & 58.3 \\
PDR & 25 & 41.7 \\
\hline
\end{tabular}

3- Mean Best Corrected Visual Acuity (BCVA), duration of DM and type of therapy:

Median BCVA was 0.287 ranges (0.02-1.0) \&Median duration of diabetes was 15.0 range $(3 \cdot 0-25 \cdot 0)$.

Among 60 patients 24patients were found on OHG (40\%) and 36 patients were found on insulin (60\%) as in table (3).

Table (3): Visual acuity, duration of DM and therapy types.

\begin{tabular}{|c|c|c|}
\hline & \multicolumn{2}{|c|}{ Mean } \\
\hline & Number & Percent \\
\hline LogMAR VA & \multicolumn{2}{|c|}{$\begin{array}{c}0.287 \pm 0.204 \\
(0.02-1.0) \\
\end{array}$} \\
\hline Duration of diabetes/years & \multicolumn{2}{|c|}{$15.0(3.0-25.0)$} \\
\hline Therapy & 24 & $40.0 \%$ \\
\hline
\end{tabular}




\section{Conjunctival Swab Culture In Diabetic Retinopathy Patients}

4- Culture results among studied cases:

Growth of some bacteria were seen in 29 patients (48.3\%) in out of 60 eyes. The commonest flora isolated was Staph CONg 31.7\%, next was candida $16.7 \%$. Others Staph aureus, Non-hemolytic streptococcus and Aspergillus were tabulated in table (4).

Mixed infections had been found in many patients.

Table (4): Culture results among studied cases.

\begin{tabular}{|l|c|c|}
\hline Culture results & $\mathrm{N}=60$ & $\%$ \\
\hline No growth & 31 & 51.7 \\
\hline Staph CONg & 19 & 31.7 \\
\hline Staph aureus & 2 & 3.3 \\
\hline Non-hemolytic streptococcus & 2 & 3.3 \\
\hline Candida & 10 & 16.7 \\
\hline Aspergillus & 1 & 1.7 \\
\hline
\end{tabular}

5- Association between culture results and sex of the studied cases:

$57.77 \%$ of male patients had sterile conjunctiva compared to $47.1 \%$ in the females. The swab culture of rest of the patients showed that Staph CONg was the predominant normal flora in both $30.8 \%$ and $32.4 \%$ in males and females respectively. However, candida species were found significantly higher in females $23.5 \%$ as in table (5).

Table (5): Association between culture results and sex of the studied cases.

\begin{tabular}{|l|c|c|c|}
\hline \multirow{2}{*}{ Culture results } & \multicolumn{2}{c|}{ Sex } & Test of \\
\cline { 2 - 4 } & Males n (\%) & Females n (\%) & significance \\
\hline No growth & $15(57.7)$ & $16(47.1)$ & $\chi^{2}=0.667 \mathrm{p}=0.414$ \\
\hline Staph CONg & $8(30.8)$ & $11(32.4)$ & $\chi^{2}=0.017 \mathrm{p}=0.896$ \\
\hline Staph aureus & $1(3.8)$ & $1(2.9)$ & FET $\mathrm{P}=1.0$ \\
\hline Non-hemolyticstreptococcus & $1(3.8)$ & $1(2.9)$ & FET $\mathrm{P}=1.0$ \\
\hline Candida & $2(7.7)$ & $8(23.5)$ & $\chi^{2}=2.66 \mathrm{p}=0.103$ \\
\hline Aspergillus & $0(0.0)$ & $1(2.9)$ & FET $\mathrm{P}=1.0$ \\
\hline
\end{tabular}

FET: Fischer exact test $\chi 2=$ Chi-Square test

6- Association between types of therapy and culture results among studied cases:

Positive conjuctival culture was found higher in patients on insulin therapy than OHG. Staph CONg, non- hemolytic streptococcus and candida were found higher in patients on insulin therapy but had no statistical significance as in table (6).

Table (6): Association between types of therapy and culture results among studied cases.

\begin{tabular}{|c|c|c|c|}
\hline Cultureresults & Oral hypoglycemicdrugs & Insulin & Test of significance \\
\hline & $\mathrm{n}=24(\%)$ & $\mathrm{n}=36(\%)$ & \\
\hline No growth & $14(58.3)$ & $17(47.2)$ & $\chi^{2}=0.712 \mathrm{p}=0.399$ \\
\hline Staph CONg & $6(25.0)$ & $13(36.1)$ & $\chi^{2}=0.822 \mathrm{p}=0.365$ \\
\hline Staph aureus & $2(8.3)$ & $0(0.0)$ & FET P $=0.156$ \\
\hline Non-hemolyticstreptococcus & $0(0.0)$ & $2(5.6)$ & FET $\mathrm{p}=0.512$ \\
\hline Candida & $3(12.5)$ & $7(19.4)$ & $\chi^{2}=0.500 \mathrm{p}=0.480$ \\
\hline Aspergillus & $0(0.0)$ & $1(2.8)$ & FET P $=1.0$ \\
\hline
\end{tabular}

FET: Fischer exact test $\chi 2$ : Chi-Square test

7- Association between culture results and stages of diabetic retinopathy among the studied cases:

Candida was found higher in stage of NPDR patients than PDR patients and had a statistical significance as in table (7). 
Staph CONg was found higher in PDR patients (40\%) than NPDR patients (25.7\%) but had no statistical significance.

Table (7): Association between culture results and stage of diabetic retinopathy among the studied cases.

\begin{tabular}{|l|c|c|c|}
\hline \multirow{2}{*}{ Culture results } & \multicolumn{2}{|c|}{ Retinopathy types } & \multirow{2}{*}{ Test of significance } \\
\cline { 2 - 3 } & $\mathrm{N}=35(\%)$ & $\mathrm{N}=25(\%)$ & \\
\hline No growth & $18(51.4)$ & $13(52.0)$ & $\chi^{2}=0.002 \mathrm{p}=0.965$ \\
\hline Staph CONg & $9(25.7)$ & $10(40.0)$ & $\chi^{2}=1.38 \mathrm{p}=0.241$ \\
\hline Staph aureus & $2(5.7)$ & $0(0.0)$ & FET $\mathrm{P}=0.506$ \\
\hline Non-hemolyticstreptococcus & $0(0.0)$ & $2(8.0)$ & FET $\mathrm{P}=0.089$ \\
\hline Candida & $9(25.7)$ & $1(4.0)$ & $\chi^{2}=4.95 \mathrm{p}=0.026^{*}$ \\
\hline Aspergillus & $1(2.9)$ & $0(0.0)$ & FET $\mathrm{P}=1.0$ \\
\hline
\end{tabular}

FET: Fischer exact test $\chi 2$ : Chi-Square test *statistically significant (if $\mathrm{p}<0.05$ )

8- Association between culture results and duration of diabetes among the studied cases:

Culture results and duration of diabetes had no statistical significance as in table (8).

Table (8): Association between culture results and duration of diabetes among the studied cases.

\begin{tabular}{|l|c|c|}
\hline \multirow{2}{*}{ Culture results } & Duration of DM/years & \multirow{2}{*}{ Test of significance } \\
\cline { 2 - 2 } & Mean \pm SD & $\mathrm{t}=0.123 \mathrm{p}=0.224$ \\
\hline No growth & $14.09 \pm 5.47$ & $\mathrm{t}=0.324 \mathrm{p}=0.747$ \\
\hline Staph CONg & $12.79 \pm 6.96$ & $\mathrm{z}=0.98 \mathrm{p}=0.786$ \\
\hline Staph aureus & $12.0 \pm 11.3$ & $\mathrm{t}=0.43 \mathrm{p}=0.669$ \\
\hline Non-hemolyticstreptococcus & $15.0 \pm 0.0$ & $\mathrm{t}=0.890 \mathrm{p}=0.377$ \\
\hline Candida & $11.60 \pm 5.68$ & $\mathrm{t}=0.521 \mathrm{p}=0.604$ \\
\hline Aspergillus & $10.0 \pm 0.0$ & \\
\hline
\end{tabular}

t: Student t test p:probability

9- Demographic characteristics distribution among cases with retinopathy:

Mean age was found higher in PDR patients than NPDR patients and NPDR patients were found higher in females and had a statistical significance as in table (9)

Table (9): Demographic characteristics distribution among cases with retinopathy.

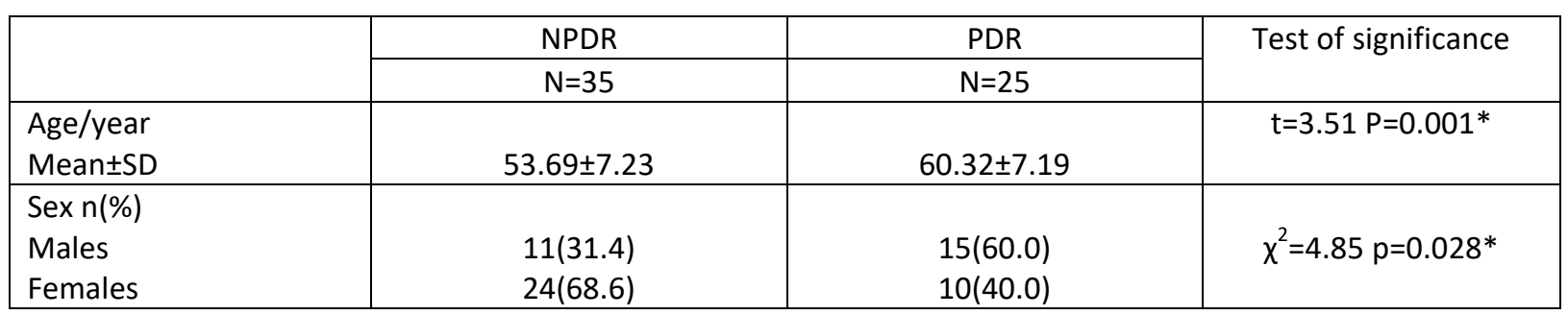

t:Student $\mathrm{t}$ test $\chi 2$ : Chi-Square test $*$ statistically significant (ifp<0.05)

10- Association between LogMAR Visual acuity, duration and treatment types distribution among cases with retinopathy:

VA was found better in NPDR than PDR and PDR had an association with increase duration of diabetes as in table (10) 
Table (10): LogMAR Visual acuity, duration and treatment types distribution among cases with retinopathy

\begin{tabular}{|c|c|c|c|}
\hline & $\mathrm{NPDR}$ & $\mathrm{PDR}$ & \multirow{2}{*}{ Test of significance } \\
\cline { 2 - 3 } & $\mathrm{N}=35$ & $\mathrm{~N}=25$ & \\
\hline LogMAR VA & $0.399 \pm 0.18$ & $0.112 \pm 0.07$ & $\mathrm{t}=7.05 \mathrm{p}<0.001^{*}$ \\
& $0.33(0.1-1.0)$ & $0.1(0.02-0.25)$ & \\
\hline Duration of & $11.60 \pm 6.21$ & $15.36 \pm 5.29$ & $\mathrm{z}=2.1 \mathrm{p}=0.02^{*}$ \\
diabetes/years & $12.0(3.0-20.0)$ & $15.0(5.0-25.0)$ & \\
\hline Therapy Oral & $21(60.0)$ & $3(12.0)$ & \multirow{2}{*}{$\chi^{2}=14.0 \mathrm{p}<0.001^{*}$} \\
hypoglycemic & $14(40.0)$ & $22(88.0)$ & \\
Insulin & &
\end{tabular}

Z:Mann Whitney $\mathrm{U}$ test t:Student $\mathrm{t}$ test $\chi^{2}$ : Chi-Square test $*_{\text {statistically significant (if }}$ $\mathrm{p}<0.05$

\section{DISCUSSION:}

Conjunctival flora forms a defensive barrier against infection, it also includes major pathogens of ocular infections. In healthy individuals, the conjunctival flora is frequently comprised of same microorganisms as the skin flora. ${ }^{(12)}$

Normal bacteriologic flora inhibits the growth and invasion of pathogenic bacteria by restricting their nutrition and limiting the space available for growth and secretion of enzymes. ${ }^{(13)}$

$\mathrm{DM}$ is one condition that may compromise immune status. Diabetics have a conjunctival flora pattern whose increased bacteria are a predominant cause of many diabetic infections. ${ }^{(14)}$

Detailed knowledge of normal conjunctival flora is essential for evaluation of culture results obtained under pathologic conditions.

Our Study aimed to detect the presence of pathogenic bacteria other than floral bacteria which are important pathogens of ocular infections in diabetic patients.

Our study included 60 eyes of 60 patients, 26 were males and 34 were females and 35 had NPDR, 25 had PDR who met the inclusion criteria.

On analyzing the demographic data, we found that the mean age was $56.45 \pm 7.87$ ranging from (33.0-73.0 years) and mean BCVA was 0.287 range $(0,02-1,0)$.

Our study showed that growth of some bacteria were seen in $48.3 \%$ in out of 60 eyes. Staph CONg 31.7\%, candida $16.7 \%$, Staph aureus 3.3\%, Non-hemolytic streptococcus $3.3 \%$ and Aspergillus 1.7\% were the most frequently isolated organisms.

Another factor that may affect the conjunctival flora is the type of hypoglycemic therapy. In our study, positive culture rates were higher among patients using insulin $52.8 \%$ compared to the $\mathrm{OHG}$ $41.7 \%$ however, the difference had no statistical significance. Staph $\mathrm{CONg}$ was found higher in patients on insulin therapy $36.1 \%$ compared to OHG $25.7 \%$ however, the difference had no statistical significance.

The most important result of our study was the higher frequency of gram-positive bacterial isolates in the diabetic retinopathy patients, candida was the second most common.

Bilen et al. ${ }^{(12)}$ results showed no growth was observed in 12 out of 17 patients $(35.4 \%)$ with type $1 \mathrm{DM}, 28$ of 66patients $(21.2 \%)$ with type $2 \mathrm{DM}$, and 25 of 50 (50\%) control subjects. Staphylococcus epidermidis (11.79\%) and Staphylococcus aureus (11.7\%) were the most frequently isolated organisms in the type $1 \mathrm{DM}$ group; S.epidermidis (24.2\%) and S.aureus (21.2\%) were the predominant organisms in the type 2 DM group. In control 
subjects, S.epidermidis (22\%), S.aureus (12\%), and Corynebacterium spp (10\%) were the most frequently isolated organisms.

These results were also consistent with those reported by Karimsab et al. ${ }^{(15)}$ in that Staphylococcus epidermidis was the most common organism isolated in diabetic and non- diabetic groups. It was isolated in $86.66 \%$ of diabetic group as compared to $36 \%$ in non-diabetic group.

Similar findings were found in another study by Tahir et al. ${ }^{(\mathbf{1 6})}$ who concluded that diabetic patients had a significantly higher number of positive conjunctival cultures and the presence of diabetic retinopathy was correlated with an increase in positive cultures and a higher proportion of staphylococcus epidermidis.

Our results were different from Adam et $a l^{(17)}$ documenting that in the diabetic group, the following bacteria were identified: S.aureus in 6 cultures (30\%); E.coli (gramnegative bacilli) in 4 cultures (20\%); CNS in 2 cultures (10\%); K.pneumoniae in 2 cultures $(10 \%)$; and more than one species of bacterium in 6 cultures (30\%).

Our results were better in documenting association between culture results, stage of diabetic retinopathy and types of therapy. Candida was found higher in stage of NPDR than PDR and had a statistical significance.

Gram-positive and gram-negative bacteria differ in their sensitivity to antibiotics. Although antibiogram was not performed in this study, there are many such studies in this literature. Coskun et al. ${ }^{(18)}$ found that among conjunctival isolates of S.aureus, $91.1 \%$ were sensitive to ofloxacin and $86.6 \%$ to ciprofloxacin, while only $8.8 \%$ were sensitive to penicillin $\mathrm{G} ; 28.8 \%$ of the isolates were methicillin resistant S.aureus and among these cultures, $38.5 \%$ showed sensitivity to ofloxacin or ciprofloxacin. In the same study, sensitivity of isolated S.epidermidis cultures to ofloxacin and ciprofloxacin was $92.5 \%$ and $91.5 \%$, respectively.

\section{Conclusion:}

The conjunctival floral pattern with increased bacteria in diabetics is a predominant cause of many diabetes related ocular infections. Ophthalmologists should be aware that conjunctival flora in diabetics differs from that in non-diabetics. This should be considered preoperatively and postoperatively, and appropriate treatment should be administered accordingly to diabetic patients. Gram-positive bacteria and candida were detected in higher ratios in the conjunctival flora of diabetic patients. Considering that flora elements may be important pathogens in ocular infections, treatment approaches to gram-positive bacterial and fungal infection should not be ignored in cases of ocular infections in diabetics.

\section{REFERENCES:}

1. Malathi J, Madhavan HN, Therese KL, Joseph PR. A hospital based study on the prevalence of conjunctivitis due to Chlamydia trachomatis. Indian J Med Res. 2003; 117: 71-75.

2. Ansari MR, Madani H, Ghaderi E. Conjunctival bacterial flora and antibiotic resistance pattern in patients undergoing cataract surgery. Pak J Med Sci. 2008; 24: 581-585.

3. Rich $\mathbf{J}$ and Lee JC. The pathogenesis of Staphylococcus aureus infection in the diabetic NOD mouse. Diabetes 2005; 54 : 2904-2910.

4. Kowluru RA and Odenbach S. Effect of long-term administration of $\alpha$-lipoic acid on retinal capillary cell death and the development of retinopathy in diabetic rats. Diabetes. 2004; 53(12):3233-8.

5. Cohen SM, Flynn HW JR, Murray TG, Smiddy WE. Endophthalmitis after pars plana vitrectomy, the post vitrectomy endophthalmitis study group. 
Ophthalmolgy. 1995; 102:705-712.

6. Cavalier-Smith $\mathrm{T}$. The neomuran origin of archaebacteria, the negibacterial root of the universal tree and bacterial megaclassification. International journal of systematic and evolutionary microbiology. 2002; 52(1):7-6.

7. Koch AL. Bacterial wall as target for attack: past, present, and future research. Clinical microbiologyreviews. 2003; 16 (4): 673-87.

8. Tang S, Orsi RH, Luo H, Ge C, Zhang G, Baker RC, Stevenson A, Wiedmann M. Assessment and comparison of molecular subtyping and characterization methods for Salmonella. Frontiers in microbiology. 2019; 10:1591.

9. Louie M, Louie L, Simor AE. The role of DNA amplification technology in the diagnosis of infectious diseases. Cmaj. 2000; 163(3):301-9.

10. Oliver JD. The viable but non culturable state in bacteria. Journal of Microbiology (Seoul, Korea). 2005; 43:93- 100.

11. Ta CN, Chang RT, Singh K, Egbert PR, Shriver EM, Blumenkranz MS, et al. Antibiotic resistance patterns of ocular bacterial flora. Ophthalmology. 2003; 110(10):1946-51.

12. Bilen $\mathrm{H}$, Ates $\mathrm{O}$, Astam $\mathrm{N}$, Uslu H, Akcay $\mathrm{G}$, Baykal O. Conjunctival flora in patients with type 1 or type 2 diabetes mellitus. Adv.
Ther. 2007; 24: 1028-1035.

13. Nahar K, Kyndt T, Hause B, Hofte M, Gheysen G. Brassinosteroids suppress rice defense against root-knot nematodes through antagonism with the jasmonate pathway. MPMI. 2013; 26:106-115.

14. Fernández-Rubio ME, Rebolledo-Lara L, Martinez-García M, Alarcón-Tomás M, Cortés-Valdés C. The conjunctival bacterial pattern of diabetics undergoing cataract surgery. Eye. 2010; 24(5):825-34.

15. Karimsab D, Razak SK. Study of aerobic bacterial conjunctival flora in patients with diabetes mellitus. Nepal

Ophthalmol. 2013; 5:28-32.

16. Tahir AM, Qadeer S, Iqbal S, Mirza MA. Aerobic bacterial conjunctival flora in diabetic Patients. Pakistan Journal of Ophthalmology. 2010; 26(4).

17. Adam M, Balcı M, Bayhan HA, İnkaya AÇ, Uyar M, Gürdal C. Conjunctival flora in diabetic and non-diabetic individuals. Turkish journal of ophthalmology. 2015; 45(5):193.

18. Coşkun M, Koçak AG, Simavlı H, Anayol MA, Toklu Y, Çelikbilek N. Analyzing normal conjunctival flora and detecting antibiogram sensitivity to flouroquinolones and penicillin derivatives. Glo-Kat. 2007; 2:167-170. 


\section{مسحة من الملتحمة لمرضي اعتلال الثبكية السكري قسم العيون جامعة عين شمس 'أسامة عبد القادر سالم ، 'رأفت علي ريحان، 'أمل يحيي المتولى أحمد، 'نسرين سعيد مدكور، 'نهى علاء الاين كحمد فهيم المليم}

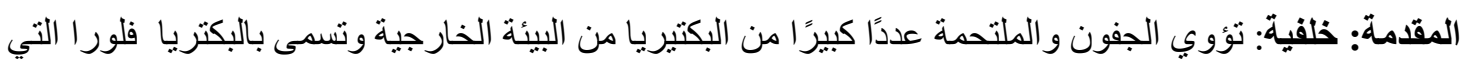

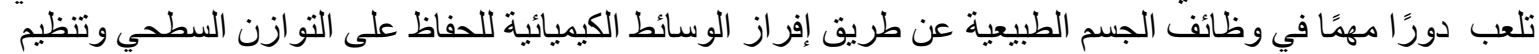

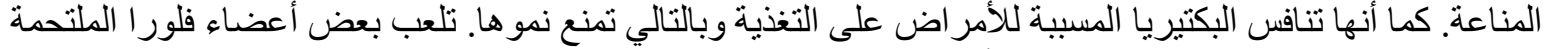

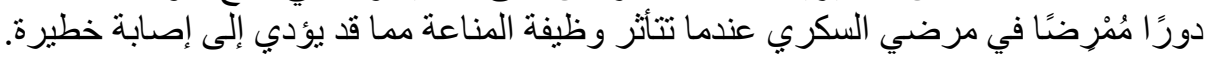

الههف من العمل: هدفت الدراسة الحالية إلى الكثف عن وجود البكتيريا المسبية للأمر اض بخلاف بكتيريريا الفلورا

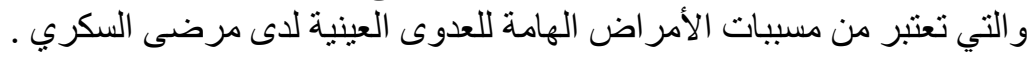

المرضى والطرق: هذه در اسة وصفية مقطعية أجريت في قسم طب العيون وقسم الأحياء الدقبقة في مستشفيات جامعة

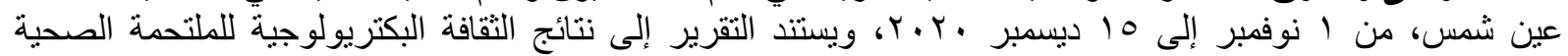

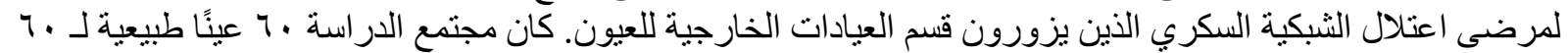

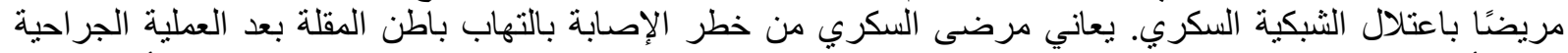

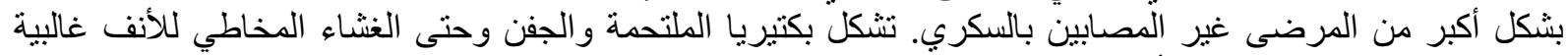
الكائنات الحية الدقيقة المسبية للأمر اض المشاركة في التهاب باطن المقلة بعد الجر احة.

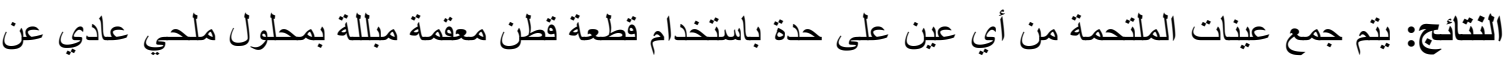

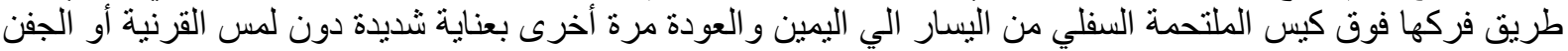

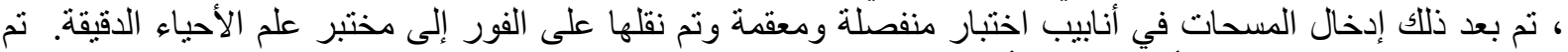

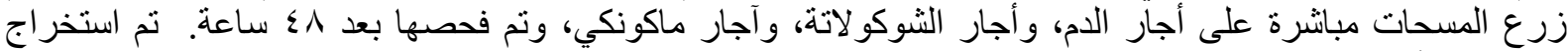

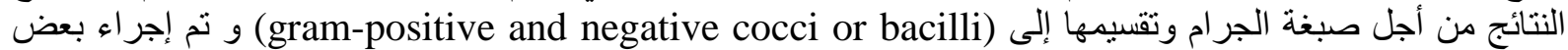
الاختبار ات للتمييز ببين البكتيريا المختلفة.

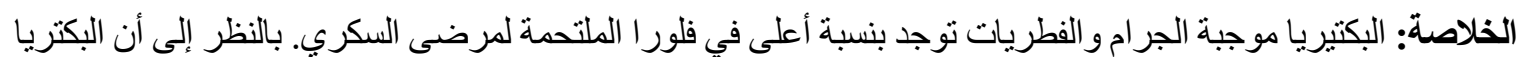

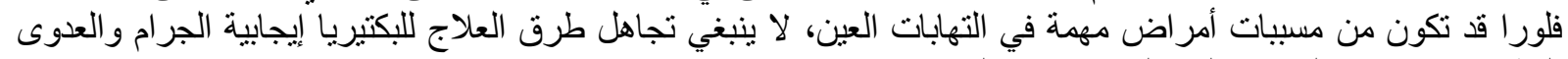
الفطرية في حالات التهابات العين لاى مرضى مرضى السكري. 